Check for updates

Cite this: J. Mater. Chem. C, 2021 , 9, 158

Received 14th September 2020 Accepted 23rd November 2020 DOI: $10.1039 / \mathrm{d} 0 \mathrm{tc} 04394 \mathrm{j}$

rsc.li/materials-c

\title{
Room temperature synthesis and characterization of novel lead-free double perovskite nanocrystals with a stable and broadband emission $\dagger$
}

\author{
Yingying Tang, ${ }^{a}$ Leyre Gomez, ${ }^{\text {ab }}$ Marco van der Laan, ${ }^{a}$ Dolf Timmerman, ${ }^{c}$ \\ Victor Sebastian, (D) def Chia-Ching Huang, ${ }^{a}$ Tom Gregorkiewicz ${ }^{a}$ and Peter Schall*a
}

\begin{abstract}
Low-dimensional and lead-free halide perovskites are of great interest for their wide application potential for optoelectronic applications. We report on the successful synthesis of novel lead-free colloidal $\mathrm{Cs}_{3} \mathrm{BiBr}_{6}$ nanocrystals (NCs) with an ultra-small size of $\sim 1.5-3 \mathrm{~nm}$ by a room temperature antisolvent process. From crystallographic characterization we show that it is critical to precisely control the ratio of precursors to obtain the pure 3-1-6 phase. The synthesis process is facile and repeatable and results in $\mathrm{Cs}_{3} \mathrm{BiBr}_{6} \mathrm{NCs}_{\mathrm{S}}$ that display stable blue emission around $438 \mathrm{~nm}$ with a relatively broad linewidth of $92.1 \mathrm{~nm}$. Low-temperature photoluminescence (PL) measurements displayed a red-shift of bandgap with decreasing temperature, which might be attributed to the thermal expansion of the lattice. In addition, the NCs demonstrate high stability at ambient conditions.
\end{abstract}

\section{Introduction}

Lead-halide perovskite nanocrystals (NCs) have recently emerged in various applications like solar cells ${ }^{1,2}$ and lightemitting diodes. ${ }^{3,4}$ The benefits of NCs in this context are the tunability of their optoelectronic properties by variation of their size, composition and surface ligands ${ }^{5}$ and the high photoluminescence quantum yield (PLQY). Other interesting properties observed in these materials include efficient carrier multiplication, ${ }^{6}$ activation of a strong light-induced forbidden exciton transition due to the influence of polaron in confined space, ${ }^{7}$ and an efficient triplet energy-transfer efficiency to pyrene complexes. ${ }^{8}$ Despite these interesting features, the important limitation of these materials in applications is the toxicity of lead; $\mathrm{Pb}^{2+}$ is soluble in water, and exposure to this has a serious impact on health. ${ }^{9}$

\footnotetext{
${ }^{a}$ Institute of Physics, University of Amsterdam, Science Park 904, 1098 XH Amsterdam, The Netherlands. E-mail: P.Schall@uva.nl

${ }^{b}$ Catalan Institute of Nanoscience and Nanotechnology, CSIC, BIST, and CIBERBBN, 08193 Bellaterra Barcelona, Spain

${ }^{c}$ Graduate School of Engineering, Osaka University, 2-1 Yamadaoka, Suita, Osaka 565-0871, Japan

${ }^{d}$ Department of Chemical Engineering and Environmental Technology, Universidad de Zaragoza, Campus Río Ebro-Edificio I + D, 50018 Zaragoza, Spain

${ }^{e}$ Instituto de Nanociencia y Materiales de Aragón (INMA),

University of Zaragoza-CSIC, c/María de Luna 3, 50018 Zaragoza, Spain

${ }^{f}$ Networking Research Center on Bioengineering Biomaterials and

Nanomedicine (CIBER-BBN), Madrid, Spain

$\dagger$ Electronic supplementary information (ESI) available. See DOI: 10.1039/ dotc04394j
}

For above reasons, there is a strong research effort into finding lead-free perovskite materials that have similar beneficial optoelectronic properties as their lead-containing counterparts. So far, several works have reported on leadfree perovskites; among these are $\mathrm{Bi}, \mathrm{Sn}$, and Ge-based perovskites. ${ }^{10-17}$ However, oxidation of $\mathrm{Sn}^{2+}$ and $\mathrm{Ge}^{2+}$ in ambient conditions limits their synthesis and application in natural environments. Bismuth-based perovskites do not suffer from this effect and are strong candidates for non-toxic and stable perovskite material. Currently, most of the Bi-based perovskites are low-dimensional structures, which could be accompanied by exotic and novel optical properties. For instance, recent reports in defect-tolerant double perovskites $\mathrm{Cs}_{2} \mathrm{ABX}_{6}$ (with A: $\mathrm{Ag}$, Cs, Na; B: In, Bi, Sb; X: Cl, Br, I), showed slow hot-carrier relaxation, dual-color emission, coexistence of direct-indirect bandgap and single emitter based warm-white emission. ${ }^{18-21}$ Especially, for NCs in the quantum confinement regime, optical and electronic properties are strongly altered. For example, $\mathrm{Cs}_{3} \mathrm{Bi}_{2} \mathrm{I}_{9} \mathrm{NCs}$ showed emission from exciton and defect states inside the bandgap, and induced broadband emission, as well as enhanced Raman scattering due to the strong exciton-ligand electronic coupling. ${ }^{22}$ Several structures have been reported in the A-Bi-X perovskite series, however, only a few of them are in the form of colloidal NCs. For example, it has been shown that relatively large NCs of $\mathrm{Cs}_{3} \mathrm{BiCl}_{6}$ could be obtained by a hotinjection method. ${ }^{23}$

Here, we report on the synthesis of stable bismuth-based double perovskite $\mathrm{NCs}, \mathrm{Cs}_{3} \mathrm{BiBr}_{6}$, using an antisolvent precipitation method at room temperature. $\mathrm{CS}_{3} \mathrm{BiBr}_{6}$ features an isolated 
$\mathrm{BiBr}_{6}$ octahedra structure, which can be considered a double perovskite. $^{24}$ The synthesized NCs have extremely small particle sizes in the range of $1.5-3 \mathrm{~nm}$, depending on the precursor ratio, and display blue emission around $438 \mathrm{~nm}$, independent of this ratio. Furthermore, they show an excellent stability at room temperature for at least 3 weeks. The synthesis is reproducible, and the NCs are obtained in a wide range of precursor ratios.

\section{Experimental section}

\section{Materials}

$\mathrm{BiBr}_{3}(\geq 98 \%), \mathrm{CsBr}$ (99.9\%), oleic acid (OA, 90\%), hydrobromic acid (HBr, 48\%) and dimethyl sulfoxide (DMSO, $\geq 99.9 \%$ ) were all purchased from Sigma-Aldrich. Isopropanol (IPA, $\geq 99.5 \%$ ) was purchased from EMD Millipore company. All materials were used as received without further purification.

\section{Synthesis of $\mathrm{Cs}_{3} \mathrm{BiBr}_{6} \mathrm{NCs}$}

For the synthesis of ligand-free $\mathrm{Cs}_{3} \mathrm{BiBr}_{6} \mathrm{NCs}, 120 \mu \mathrm{mol} \mathrm{CsBr}$ (25.5 mg) and $30 \mu \mathrm{mol} \mathrm{BiBr}_{3}(13.45 \mathrm{mg})$ were dissolved in $2 \mathrm{~mL}$ DMSO at room temperature or $70{ }^{\circ} \mathrm{C}$ to form the precursor solution. Alternatively, $90 \mu \mathrm{mol} \mathrm{CsBr}(19.2 \mathrm{mg}), 30 \mu \mathrm{mol} \mathrm{BiBr}_{3}$ $(13.45 \mathrm{mg})$ and $\mathrm{HBr}(100 \mu \mathrm{L})$ were dissolved in $2 \mathrm{~mL}$ DMSO to form precursor solution. $200 \mu \mathrm{L}$ of the above precursor solution was injected into $5 \mathrm{~mL}$ IPA, under vigorous stirring for one minute. Then the solution was centrifuged at $10000 \mathrm{rpm}$ for 5 min to discard the large particles. After that, clear colloidal NCs dispersed in IPA were obtained. For the synthesis of OA-capped $\mathrm{Cs}_{3} \mathrm{BiBr}_{6} \mathrm{NCs}$, all the procedures were the same with the only difference being the addition of $300 \mu \mathrm{L}$ OA into the precursor.

\section{Measurement and characterization}

Materials characterizations. Samples were prepared by dropcasting the NCs containing solution onto a Lacey grid for measurements. The grids made from $\mathrm{Cu}$ were used as support materials for Transmission Electron Microscope (TEM) imaging. TEM imaging was conducted at $300 \mathrm{kV}$ on an ultra-high resolution imaging Titan Cube 0 Transmission Electron Microscope from FEI Company. The microscope is equipped with a SuperTwin ${ }^{\circledR}$ objective lens and a CETCOR Cs-objective corrector from CEOS Company allowing a point to point resolution of $0.08 \mathrm{~nm}$. High-angle annular dark-field-scanning transmission electron microscopy (HAADF-STEM) and energy dispersive X-ray (EDX) measurements were also performed on the same system. The phase and purity of all samples were characterized by powder X-ray diffraction (XRD) with $\mathrm{Cu} \mathrm{K} \alpha_{1}(\lambda=1.5406 \AA)$ radiation (Rigaku MiniFlex-II). X-ray Photoelectron Spectroscopy analyses were carried out with a Kratos Axis SUPRA spectrometer using a monochromatic Al K(alpha) source $(15 \mathrm{kV})$. Small crystals of $\mathrm{Cs}_{3} \mathrm{BiBr}_{6}$ obtained from previous work were selected and data collections were performed on a Bruker APEX-II CCD diffractometer equipped with graphite monochromated Mo $\mathrm{K}_{\alpha}$ radiation $(\lambda=0.71073 \AA)$ at $120 \mathrm{~K}^{24}$ The data sets were corrected for Lorentz and polarization factors as well as for absorption by using a multi-scan method. ${ }^{25}$ The structure was solved using direct methods and refined by full-matrix least-squares fitting on $F^{2}$ by SHELX-97. ${ }^{26}$ All non-H atoms were refined using anisotropic thermal parameters. The final refined structural parameters were checked by using the PLATON program. $^{27}$

\section{Optical measurements}

The absorption spectra was obtained by measuring the transmission on A LAMBDA 950 UV/vis/NIR spectrophotometer (PerkinElmer). The separately measured absorption spectrum of the solvent (IPA) was subtracted from the NC spectrum. PL spectra were determined with a Jobin Yvon FluoroLog spectrofluorometer (Horiba). As excitation source, a $450 \mathrm{~W}$ xenon lamp coupled to a monochromator was used. The PL data was collected for excitation wavelength of $355 \mathrm{~nm}$. All spectra are corrected for the spectral sensitivity of the spectrofluorometer. The determination of the PLQY was based on an integrating sphere methodology. ${ }^{28}$ Time-resolved PL measurements were performed using a LifeSpecII time correlated single photon counting (TCSPC) spectrometer series, 100 ps was used as excitation source. A right angle between the excitation and emission beam paths was maintained to reduce detection of scattered excitation light. For the low temperature PL setup, a xenon lamp (L2273 Hamamastu) coupled to a Solar MSA 130 double grating monochromator was used as an excitation source. The collected emission was dispersed by an M266 (Solar LS) monochromator coupled to a silicon CCD (Horiba scientific). The sample was cooled in a CCC1104 (Oxford inst.) cryostat, which was used in combination with a closed-cycle helium compressor (Cryomech). The sample was placed on a cold finger in a static exchange gas to ensure the temperature setting was obtained. A $355 \mathrm{~nm}$ excitation wavelength was used to collect the low temperature PL spectra.

\section{Results and discussion}

The double perovskite $\mathrm{Cs}_{3} \mathrm{BiBr}_{6}$ crystallizes in the orthorhombic system in a space group of $P b c m$, with $a=8.689(2) \AA$, $b=13.628(1) \AA, c=27.694(9) \AA{ }^{24}{ }^{24}$ Each $\mathrm{Bi}$ is coordinated with six $\mathrm{Br}$ atoms, forming $\mathrm{BiBr}_{6}$ octahedra. $\mathrm{BiBr}_{6}$ octahedra are separated from each other, forming a zero-dimensional perovskite structure, as shown in Fig. 1a. In the present work, the $\mathrm{Cs}_{3} \mathrm{BiBr}_{6}$ NCs were synthesized by an antisolvent precipitation method. For the synthesis of the nanomaterials, a precise control of the precursor ratios between $\mathrm{BiBr}_{3}$ and $\mathrm{CsBr}$ was required. As control experiments, different ratios of precursors were tried to obtain the NCs. To exclude the effects of excess of $\mathrm{Cs}^{+}$on the synthesis, $\mathrm{HBr}$ was instead used to introduce excess $\mathrm{Br}^{-}$while keeping the stoichiometric ratio between $\mathrm{CsBr}$ and $\mathrm{BiBr}_{3}$. $\mathrm{Cs}_{3} \mathrm{BiBr}_{6}$ NCs could also be obtained using $\mathrm{HBr}$ as precursor (Fig. 1b). Controlling the ratios of the precursors is critical for the formation of the NCs, as we confirmed by a series of control experiments. As displayed in Fig. S1a (ESI $\dagger$ ), when the ratio $\left(\mathrm{CsBr} / \mathrm{BiBr}_{3}\right)$ was below $4, \mathrm{Cs}_{3} \mathrm{Bi}_{2} \mathrm{Br}_{9}$ NCs or a mixture of 

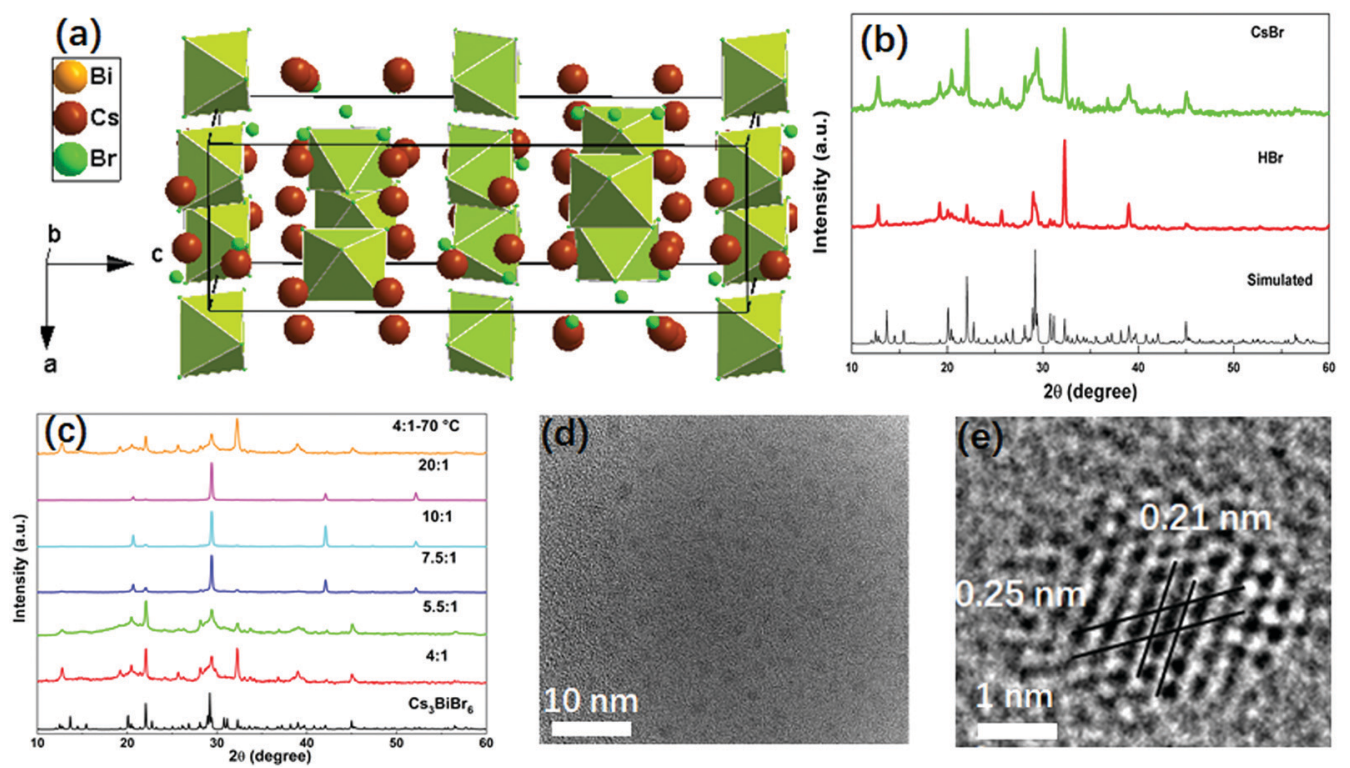

Fig. 1 (a) Crystal structure of $\mathrm{Cs}_{3} \mathrm{BiBr}_{6}$. (b) XRD pattern of $\mathrm{Cs}_{3} \mathrm{BiBr}_{6} \mathrm{NCs}$ with addition of $\mathrm{CsBr}$ or $\mathrm{HBr}$ precursors and the simulated XRD pattern (CCDC, $\# 1877001$ ). (c) $X R D$ pattern of $\mathrm{CS}_{3} \mathrm{BiBr}_{6}$ for several precursor ratios of $\mathrm{CsBr} / \mathrm{BiBr}_{3}$ at room temperature and at $70{ }^{\circ} \mathrm{C}$. (d) Representative $\mathrm{TEM}$ image for $\mathrm{Cs}_{3} \mathrm{BiBr}_{6}-5.5 \mathrm{NCs}$. (e) HRTEM image with an atomic resolution for a $\mathrm{Cs}_{3} \mathrm{BiBr}_{6}-5.5 \mathrm{NC}$.

$\mathrm{Cs}_{3} \mathrm{Bi}_{2} \mathrm{Br}_{9}$ and $\mathrm{Cs}_{3} \mathrm{BiBr}_{6}$ NCs were obtained. In contrast, for ratios between 4 and 7.5 , we clearly observed the $\mathrm{Cs}_{3} \mathrm{BiBr}_{6}$ phase alone, as shown by the XRD patterns in Fig. 1c, which match well with its simulated pattern. When the ratios are larger than 7.5, several dominant peaks are displayed, i.e. (136), (410), (331), (130), (025) crystalline planes for $\mathrm{Cs}_{3} \mathrm{BiBr}_{6} \cdot{ }^{24}$ Peaks from $\mathrm{CsBr}$ and $\mathrm{BiBr}_{3}$ precursor impurities can be excluded by comparison with their XRD peaks. We thus consider that the morphology of the NCs may differ for lower precursor ratios. In order to check this, we characterized the NCs with different ratios of precursors. For convenience we use $\mathrm{Cs}_{3} \mathrm{BiBr}_{6}-4$, $\mathrm{Cs}_{3} \mathrm{BiBr}_{6}-5.5, \mathrm{Cs}_{3} \mathrm{BiBr}_{6}-7.5, \mathrm{Cs}_{3} \mathrm{BiBr}_{6}-10, \mathrm{Cs}_{3} \mathrm{BiBr}_{6}-20$ to indicate molar ratios of $\mathrm{CsBr} / \mathrm{BiBr}_{3}$ precursors of 4, 5.5, 7.5, 10, 20, respectively. Corresponding XRD patterns plotted in Fig. 1c show that the peaks are robust. Furthermore, to investigate if the $\mathrm{Cs}_{3} \mathrm{BiBr}_{6}$ phase is still stable at high temperature, the reaction temperature was increased to $70{ }^{\circ} \mathrm{C}$. The corresponding XRD pattern shows that $\mathrm{Cs}_{3} \mathrm{BiBr}_{6}$ NCs could also be obtained.

Fig. 1d and e present HRTEM images of $\mathrm{Cs}_{3} \mathrm{BiBr}_{6}-5.5$ NCs. The individual NCs could be observed with an average size of around $1.6 \mathrm{~nm}$ (inset of Fig. S2a, ESI $\dagger$ ). For $\mathrm{Cs}_{3} \mathrm{BiBr}_{6}-10$, the average size NCs is about $2.3 \mathrm{~nm}$ (Fig. S2b and d, ESI $\dagger$ ). Also, a branch-like morphology of NCs was observed (Fig. S2c, ESI $\dagger$ ), which might induce the dominant orientation of NCs corresponding to the pronounced XRD diffraction peaks, for example, the XRD diffraction peak at $\sim 29^{\circ}$ in the XRD pattern. We conclude by comparison with simulated XRD patterns ( $\mathrm{CsBr}$, $F m \overline{3} m$; CsBr, $P m \overline{3} m$; and $\left.\mathrm{BiBr}_{3}, P 2_{1} / c\right)$ and $\mathrm{Cs}_{3} \mathrm{BiBr}_{6}$ that these dominant XRD diffraction peaks e.g. XRD diffraction peak at $\sim 29^{\circ}$, cannot result from the precursors (Fig. S3a, ESI $\dagger$ ). Meanwhile, as shown in the zoomed-in $\mathrm{XRD}$ for $\mathrm{Cs}_{3} \mathrm{BiBr}_{6}-7.5$, $\mathrm{Cs}_{3} \mathrm{BiBr}_{6}-10, \mathrm{Cs}_{3} \mathrm{BiBr}_{6}-20 \mathrm{NCs}$ (Fig. S3b, ESI $\dagger$ ), all the dominant peaks can be well identified by the simulated $\mathrm{Cs}_{3} \mathrm{BiBr}_{6} \mathrm{XRD}$ pattern. Yet, in Fig. 1c, many of the weak diffraction peaks are hidden by the pronounced peaks with high intensity in these three samples. In the HRTEM image of $\mathrm{Cs}_{3} \mathrm{BiBr}_{6}-5.5 \mathrm{NCs}$, the clear lattice fringes of $0.21 \mathrm{~nm}$ and $0.25 \mathrm{~nm}$ in a single $\mathrm{NC}$ could be related to the crystalline planes (412) and (244) of $\mathrm{Cs}_{3} \mathrm{BiBr}_{6}$, respectively, while a lattice spacing of $0.22 \mathrm{~nm}$ corresponds to the (111) plane (Fig. S2d, ESI $\dagger$ ). In order to check the chemical composition of these NCs, XPS measurements on $\mathrm{Cs}_{3} \mathrm{BiBr}_{6}-5.5$ NCs were conducted, which indeed show characteristic peaks of $\mathrm{Cs}, \mathrm{Bi}$ and $\mathrm{Br}$ (Fig. S4, ESI $\dagger$ ). The detailed elemental ratio between $\mathrm{Cs}$, $\mathrm{Bi}$, and $\mathrm{Br}$ elements was calculated as $\mathrm{Cs}_{2.3} \mathrm{BiBr}_{6.1}$, which is close to the reported chemical formula.

The optical properties of $\mathrm{Cs}_{3} \mathrm{BiBr}_{6}$ NCs are shown in Fig. 2 and Fig. S5 (ESI $\dagger$ ). Fig. 2a shows that the absorption peak of the NCs appears around $385 \mathrm{~nm}$, which is similar to the previous result through a halide exchange reaction from $\mathrm{Cs}_{3} \mathrm{BiCl}_{6}{ }^{23}$ and its behaviour is independent of the precursor ratio (Fig. 2b). The absorption spectra for $\mathrm{Cs}_{3} \mathrm{Bi}_{2} \mathrm{Br}_{9}$ NCs display an absorption onset of around $440 \mathrm{~nm}$ (Fig. $\mathrm{S} 1 \mathrm{~b}$, ESI $\dagger$ ), which is different from the onset at $385 \mathrm{~nm}$ for $\mathrm{Cs}_{3} \mathrm{BiBr}_{6}$ NCs. This further excludes the possibility of impurities from large amount of $\mathrm{Cs}_{3} \mathrm{Bi}_{2} \mathrm{Br}_{9}$ NCs. We thus hypothesize that it may be the crystallization pathway that makes it necessary to mix with a molar ratio of $4: 1$ or more to obtain the pure phase. The PL peak is located at $438 \mathrm{~nm}$ and the bandgap was determined from the Tauc plot in Fig. S6 (ESI $\dagger$ ) as $2.89 \mathrm{eV}(429 \mathrm{~nm})$. Similar robustness as the absorption spectra is observed for the PL spectra of the different materials as shown in Fig. 2c, which are nearly identical. The peak positions display no obvious changes upon increasing $\mathrm{CsBr}$, which is consistent with the TEM results. This can be well explained by the small Bohr radius of $\mathrm{Cs}_{3} \mathrm{BiBr}_{6} \mathrm{NCs}(\sim 0.5 \mathrm{~nm}) .{ }^{29}$ The as-synthesized $\mathrm{Cs}_{3} \mathrm{BiBr}_{6}$ NCs with size of $1.5-3 \mathrm{~nm}$ are 

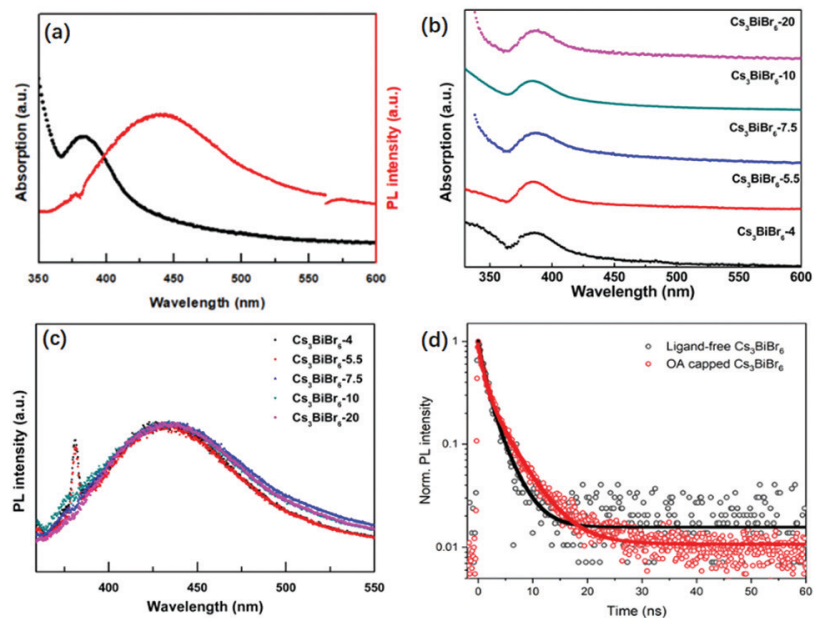

Fig. 2 Optical properties for ligand-free $\mathrm{Cs}_{3} \mathrm{BiBr}_{6} \mathrm{NCs}$ : (a) absorption spectra and PL spectra for $\mathrm{Cs}_{3} \mathrm{BiBr}_{6}-5.5 \mathrm{NCs}$. (b) Absorption spectra for different ratios of precursors. (c) PL spectra for the addition of different ratios of precursors. (d) TR-PL kinetics of $\mathrm{Cs}_{3} \mathrm{BiBr}_{6}-5.5 \mathrm{NCs}$ with and without OA capping measured with TCSPC ( $375 \mathrm{~nm}$ pump) fitted with a bi-exponential function.

around 3 to 6 times larger than this Bohr radius, and are thus not expected to display any significant quantum confinement effects, resulting in robust PL emission peaks within this size regime. We have determined the PLQY for the $\mathrm{Cs}_{3} \mathrm{BiBr}_{6} \mathrm{NCs}$ passivated by OA ligands as $22 \%$. However, we found that the OA itself has a strong emission band partly overlapping with the emission of the NCs, as shown in Fig. S7a (ESI $\dagger$ ). For comparison, the PL spectra of OA-capped NCs are also shown in Fig. S7b (ESI $\dagger$ ), which reveal a strong emission signal in the range of 340-500 $\mathrm{nm}$. A similar phenomenon has also been reported previously. ${ }^{22}$ We therefore prepared fresh samples without ligands. These demonstrated a considerably lower PLQY, which was difficult to determine accurately.

To obtain more insight, we studied the photophysics of both ligand-free and OA-capped $\mathrm{Cs}_{3} \mathrm{BiBr}_{6}-5.5$ NCs by time-resolved photoluminescence (TRPL) under excitation of a $375 \mathrm{~nm}$ laser. The results are shown in Fig. 2d. The PL decays were fitted with a bi-exponential function, both with a fast component $\left(\tau_{1}=1.0 \mathrm{~ns}\right.$ ) and a slower component of 2.8 and $4.3 \mathrm{~ns}$ for the ligand-free and OA capped NCs, respectively (ligand-free: $A_{1}=$ $A_{2}=0.5$; OA-capped: $\left.A_{1}=0.55, A_{2}=0.45\right)$. The longer lifetime is comparable to other reported lead-free perovskite NCs: average lifetimes of $4.3 \mathrm{~ns}$ in $\mathrm{Cs}_{3} \mathrm{Sb}_{2} \mathrm{Br}_{9} \mathrm{NCs}^{25}$ and $2.1 \mathrm{~ns}$ in $\mathrm{Cs}_{3} \mathrm{Bi}_{2} \mathrm{Br}_{9}$ $\mathrm{NCs}^{30}$ have been obtained. The increase in lifetime for OA-capped NCs cannot fully explain the much higher PLQY that we observe as compared to ligand-free NCs. It is known from studies on carrier dynamics in other lead-free NCs that they typically show an ultrafast ( $\ll 100 \mathrm{ps})$ carrier trapping process that strongly limits their PLQY. ${ }^{31-34}$ Passivation by OA alleviates this process and increases the PLQY. Since the time resolution of our system is longer than such and ultrafast trapping process, we do not observe it in the PL dynamics. However, we note that the longer decay time we observe for OA-capped NCs indicates that it is either due to OA-related passivation, or direct emission from the OA ligands. Future studies on carrier dynamics will be necessary to point out the exact origin.

One important characteristic for understanding their photophysical properties, especially those depending on photoexcited charge carriers and thus applicability of photonic or optoelectronic applications, is the absorption cross-section. We have determined the absorption cross-section $\sigma$ from linear absorption measurements using the following equation:

$$
T=\mathrm{e}^{(-l \times \sigma \times n)}
$$

where $T$ is the transmittance, $l$ is the path length and $n$ is the density of the NCs. For the cuvette used in our lab, the path length is $l=1 \mathrm{~cm}$. From the measured transmittance $T=0.35$ and the NC concentration of $80 \mathrm{mg} \mathrm{mL}{ }^{-1}$, the absorption cross-section for the $\mathrm{Cs}_{3} \mathrm{BiBr}_{6} \mathrm{NCs}$ is calculated to be $2.4 \times 10^{-17} \mathrm{~cm}^{2} .{ }^{35}$ This value is about an order of magnitude lower than what would be estimated from extrapolating the size-dependent cross-section of the well-known $\mathrm{CsPbBr}_{3}$ QDs. $^{36}$

Due to the low PLQY of $\mathrm{Cs}_{3} \mathrm{BiBr}_{6}$ at room temperature, we also performed PL measurements at low temperatures in order to obtain information about processes that are responsible for PL quenching at higher temperatures. The PL spectra recorded for a temperature range of 50-300 $\mathrm{K}$ are displayed in Fig. 3a and Fig. S8 (ESI $\dagger$ ). They reveal two important features: an increase of the PL intensity for lower temperatures, accompanied by a red-shift. The integrated PL intensity as a function of reciprocal temperature is depicted in Fig. $3 \mathrm{~b}$. We use this to determine the activation energy of the non-radiative process responsible for the thermal quenching, by fitting with the Arrhenius formula:

$$
\operatorname{PL}(T)=I_{0} /\left(1+A \times \exp \left(-\varepsilon / k_{\mathrm{B}} T\right)\right)
$$

where $I_{0}$ and $A$ are free parameters, $\varepsilon$ is the effective activation energy, and $k_{\mathrm{B}}$ is Boltzmann's constant. The indicated fit gives an activation energy of $41 \mathrm{meV}$, which is of the same order of magnitude as that of other perovskites. ${ }^{37-39}$ The red shift in band gap at low temperature has been found in $\mathrm{CsPBr}_{3}$ quantum dots, which was attributed to the thermal expansion of the lattice limiting the interaction between valence orbitals and leading to the narrowing of the valence bandwidth and increase of the forbidden gap. ${ }^{40}$ we have measured the crystal structure of the $\mathrm{Cs}_{3} \mathrm{BiBr}_{6}$ single crystals at $120 \mathrm{~K}$ based on the previously reported work. ${ }^{24}$ At $120 \mathrm{~K}, \mathrm{Cs}_{3} \mathrm{BiBr}_{6}$ single crystals
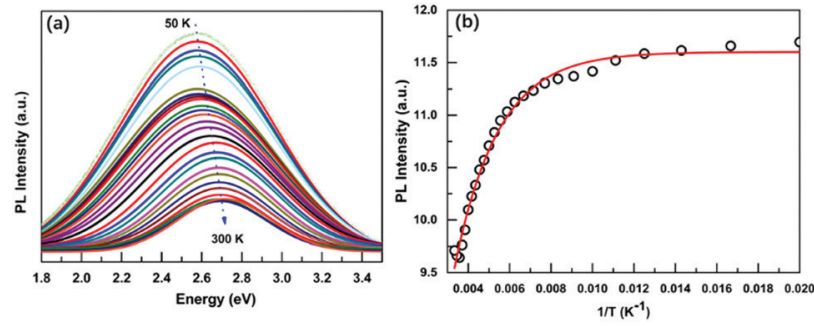

Fig. 3 (a) Temperature-dependent PL spectra of OA-capped $\mathrm{Cs}_{3} \mathrm{BiBr}_{6}$ NCs at the temperature range of 50-300 K. (b) Integrated PL intensity of $\mathrm{Cs}_{3} \mathrm{BiBr}_{6} \mathrm{NCs}$ versus inverse temperature and the Arrhenius fitting. 

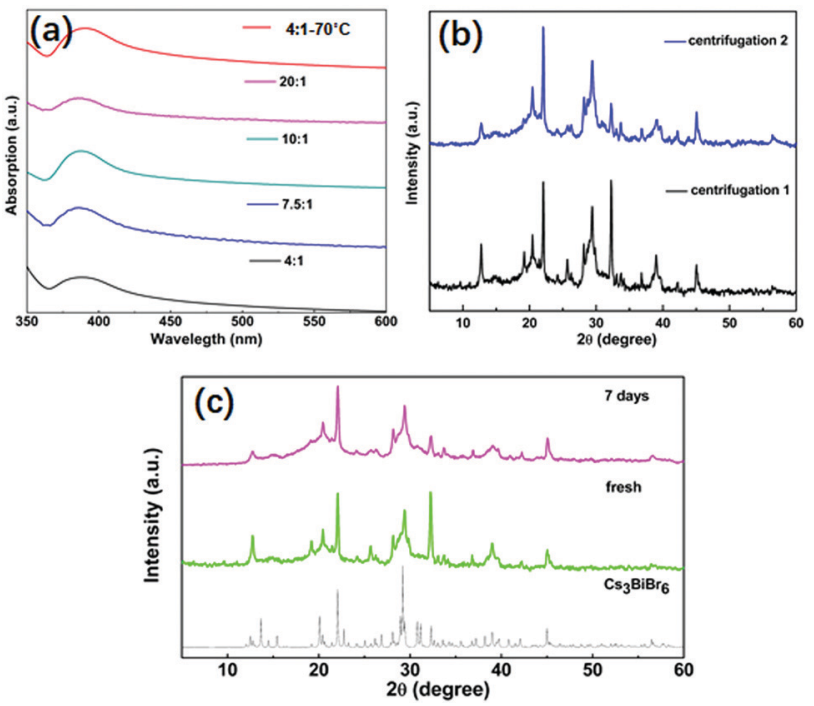

Fig. 4 Stability for $\mathrm{C}_{3} \mathrm{BiBr}_{6}$ ligand-free NCs. (a) UV-vis absorption spectra after wash treatment with IPA twice. (b) XRD pattern after washing treatment by IPA twice. (c) XRD patterns for fresh and aged samples after 7 days.

display the same structure (space group, Pbcm with $a=8.637(3) \AA$, $b=13.495(6) \AA, c=27.532(6) \AA$ ), as at room temperature (space group of $\mathrm{Pbcm}$ with $a=8.689(2) \AA, \quad b=13.628(1) \AA$, and $c=27.694(9) \AA ̊)$, see Table S1 (ESI $\dagger$ ). This indicates that at low temperature, no phase transition occurs.

The stability of NCs is critical for their potential applications. We investigated various aspects of their stability which are displayed in Fig. 4. First, the stability against an IPA washing treatment was investigated and as shown in Fig. 4a. Before the treatment, the absorption peak for $\mathrm{Cs}_{3} \mathrm{BiBr}_{6}$ NCs appears at around $385 \mathrm{~nm}$. After one additional washing treatment by IPA, the absorption peaks for all samples are still at the same position, consistent with the different kinds of ratios of precursors and also for higher temperature. This demonstrates the stability of $\mathrm{Cs}_{3} \mathrm{BiBr}_{6}$ NCs against washing treatment with IPA solvent. Additionally, we used XRD to check the chemical composition after the IPA treatment (Fig. 4b), after single and double washing. Compared to the XRD in Fig. 1b, no impurities or other phases were found in the XRD data, supporting the conclusion that these NCs are stable against IPA solvent washing. Another important factor for applications is the air stability. The XRD spectra for a fresh and aged sample, after storage at ambient condition for 7 days, were investigated as shown in Fig. 4c. In addition, the optical stability was determined after 3 weeks, as shown in Fig. S9 $(\mathrm{ESI} \dagger)$. The PL peak and intensity were nearly identical after storing in ambient conditions, demonstrating their air stability.

\section{Conclusions}

Here, we report on successful synthesis and characterization of novel lead-free $\mathrm{Cs}_{3} \mathrm{BiBr}_{6} \mathrm{NCs}$, obtained by a room temperature synthesis method. The synthesis process is facile and repeatable and generates NCs with an ultra-small size of $\sim 1.5-3 \mathrm{~nm}$. In order to obtain pure $\mathrm{Cs}_{3} \mathrm{BiBr}_{6}$ NCs, an excess amount of $\mathrm{Br}^{-}$is necessary. Otherwise, another bismuth phase, $\mathrm{Cs}_{3} \mathrm{Bi}_{2} \mathrm{Br}_{9}$, will also be one of the products. The $\mathrm{Cs}_{3} \mathrm{BiBr}_{6}$ NCs display stable blue emission, centred at $438 \mathrm{~nm}$, with a broad linewidth of $92.1 \mathrm{~nm}$. At ambient conditions, the NCs display a high stability against the solvent and ambient air. This work proposes a promising low-dimensional candidate for lead-free optoelectronic applications.

\section{Conflicts of interest}

There are no conflicts to declare.

\section{Acknowledgements}

We are grateful for the Dutch Technology Foundation STW, The Netherlands Organization for Scientific Research (NWO), and the Joint Solar Program (JSP III, 680-91-011) of The NWO for financial support. We acknowledge Arnon Lesage and Dido Van der Gon for their kind help. V. S. acknowledges the LMA-INA for offering access to their instruments and expertise.

\section{Notes and references}

1 A. Swarnkar, A. R. Marshall, E. M. Sanehira, B. Chernomordik, D. T. Moore, J. A. Christians, T. Chakrabarti and J. M. Luther, Science, 2016, 354, 92.

2 L. M. Wheeler, E. M. Sanehira, A. R. Marshall, P. Schulz, M. Suri, N. C. Anderson, J. A. Christians, D. Nordlund, D. Sokaras and T. Kroll, J. Am. Chem. Soc., 2018, 140, 10504. 3 J. Sun, J. Yang, J. I. Lee, J. H. Cho and M. S. Kang, J. Phys. Chem. Lett., 2018, 97, 1573.

4 J. Xing, Y. B. Zhao, M. Askerka, L. N. Quan, X. W. Gong, W. J. Zhao, J. X. Zhao, H. R. Tan, G. K. Long, L. Gao, Z. Y. Yang, O. Voznyy, J. Tang, Z.-H. Lu, Q. H. Xiong and E. H. Sargent, Nat. Commun., 2018, 9, 3541.

5 Y.-F. Li, J. Feng and H.-B. Sun, Nanoscale, 2019, 11, 19119.

6 C. de Weerd, L. Gomez, A. Capretti, D. M. Lebrun, E. Matsubara, J. H. Lin, M. Ashida, F. C. M. Spoor, L. D. A. Siebbeles, A. J. Houtepen, K. Suenaga, Y. Fujiwara and T. Gregorkiewicz, Nat. Commun., 2018, 9, 4199.

7 D. Rossi, H. Wang, Y. T. Dong, T. Qiao, X. F. Qian and D. H. Son, ACS Nano, 2018, 12, 12436.

8 X. Luo, R. C. Lai, Y. L. Li, Y. Y. Han, G. J. Liang, X. Liu, T. Ding, J. H. Wang and K. F. Wu, J. Am. Chem. Soc., 2019, 141, 4186.

9 G. Flora, D. Gupta and A. Tiwari, Interdiscip. Toxicol., 2012, $5,47$.

10 Y. Q. Hu, T. Qiu, F. Bai, W. Ruan and S. F. Zhang, Adv. Energy Mater., 2018, 8, 1703620.

11 B.-W. Park, B. Philippe, X. L. Zhang, H. Rensmo, G. Boschloo and E. M. J. Johansson, Adv. Mater., 2015, 27, 6806.

12 T.-B. Song, T. Yokoyama, S. Aramaki and M. G. Kanatzidis, ACS Energy Lett., 2017, 24, 897. 
13 S. Y. Shao, J. Liu, G. Portale, H. H. Fang, G. R. Blake, G. H. ten Brink, L. J. A. Koster and M. A. Loi, Adv. Energy Mater., 2018, 8, 1702019.

14 W. J. Ke and M. G. Kanatzidis, Nat. Commun., 2019, 10, 965.

15 S. P. Liu, B. Yang, J. S. Chen, D. H. Wei, D. Y. Zheng, Q. K. Kong, W. Q. Deng and K. L. Han, Angew. Chem., Int. Ed., 2020, 59, 1.

16 B. Yang and K. L. Han, Acc. Chem. Res., 2019, 52, 3188.

17 M. Y. Cong, B. Yang, F. Hong, T. C. Zheng, Y. B. Sang, J. W. Guo, S. Q. Yang and K. L. Han, Sci. Bull., 2020, 65, 1078.

18 J. J. Luo, X. M. Wang, S. R. Li, J. Liu, Y. M. Guo, G. D. Niu, L. Yao, Y. H. Fu, L. Gao, Q. S. Dong, C. Y. Zhao, M. Y. Leng, F. S. Ma, W. X. Liang, L. D. Wang, S. Y. Jin, J. B. Han, L. J. Zhang, J. Etheridge, J. B. Wang, Y. Y. Yan, E. H. Sargent and J. Tang, Nature, 2018, 563, 541.

19 B. Yang, X. Mao, F. Hong, W. W. Meng, Y. X. Tang, X. S. Xia, S. Q. Yang, W. Q. Deng and K. L. Han, J. Am. Chem. Soc., 2018, 140, 17001.

20 Z. W. Xiao, K.-Z. Du, W. W. Meng, J. B. Wang, D. B. Mitzi and Y. F. Yan, J. Am. Chem. Soc., 2017, 139, 6054.

21 F. Locardi, M. Cirignano, D. Baranov, Z. Y. Dang, M. Prato, F. Drago, M. Ferretti, V. Pinchetti, M. Fanciulli, S. Brovelli, L. D. Trizio and L. Manna, J. Am. Chem. Soc., 2018, 140, 12989.

22 G. M. Paternò, N. Mishra, A. J. Barker, Z. Y. Dang, G. Lanzani, L. Manna and A. Petrozza, Adv. Funct. Mater., 2018, 29, 1805299.

23 H. J. Yang, T. Cai, E. Liu, K. Hills-Kimball, J. B. Gao and O. Chen, Nano Res., 2020, 13, 282.

24 Y. Y. Tang, M. L. Liang, B. D. Chang, H. Y. Sun, K. B. Zheng, T. Pullerits and Q. J. Chi, J. Mater. Chem. C, 2019, 7, 3369.

25 CrystalClear, version 1.3.5, Rigaku Corp., The Woodlands, TX, 1999.

26 G. M. Sheldrick, Crystallographic Software Package, SHELXTL, version 5.1, Bruker AXS, Madison, WI, 1998.

27 A. L. Spek, J. Appl. Crystallogr., 2003, 36, 7.
28 J. Zhang, Y. Yang, H. Deng, U. Farooq, X. K. Yang, J. Khan, J. Tang and H. Song, ACS Nano, 2017, 11, 9294.

29 M. N. Tran, I. J. Cleveland and E. S. Aydil, J. Mater. Chem. C, 2020, 8, 10456.

30 M. Y. Leng, Y. Yang, K. Zeng, Z. W. Chen, Z. F. Tan, S. R. Li, J. H. Li, B. Xu, D. B. Li, M. P. Hautzinger, Y. P. Fu, T. Y. Zhai, L. Xu, G. D. Niu, S. Jin and J. Tang, Adv. Funct. Mater., 2018, 28, 1704446.

31 M. A. Boles, D. Ling, T. Hyeon and D. V. Talapin, Nat. Mater., 2016, 15, 141.

32 B. Yang, J. S. Chen, F. Hong, X. Mao, K. B. Zheng, S. Q. Yang, Y. J. Li, T. Pullerits, W. Q. Deng and K. L. Han, Angew. Chem., Int. Ed., 2017, 56, 12471.

33 B. Yang, J. S. Chen, S. Q. Yang, F. Hong, L. Sun, P. G. Han, T. Pullerits, W. Q. Deng and K. L. Han, Angew. Chem., Int. Ed., 2018, 57, 5359.

34 B. Yang, F. Hong, J. S. Chen, Y. X. Tang, L. Yang, Y. B. Sang, X. S. Xia, J. W. Guo, H. X. He, S. Q. Yang, W. Q. Deng and K. L. Han, Angew. Chem., Int. Ed., 2019, 58, 2278.

35 F. R. Hu, H. C. Zhang, C. Sun, C. Y. Yin, B. H. Lv, C. F. Zhang, W. W. Yu, X. Y. Wang, Y. Zhang and M. Xiao, ACS Nano, 2015, 9, 12410.

36 J. Puthenpurayil, O. Hsu-Cheng Cheng, T. Qiao, D. Rossi and D. H. Son, J. Chem. Phys., 2019, 151, 154706.

37 T. J. Savenije, C. S. Ponseca Jr, L. Kunneman, M. Abdellah, K. B. Zheng, Y. X. Tian, Q. S. Zhu, S. E. Canton, I. G. Scheblykin, T. Pullerits, A. Yartsev and V. Sundström, J. Phys. Chem. Lett., 2014, 5, 2189.

38 S. Tombe, G. Adam, H. Heilbrunner, D. H. Apaydin, C. Ulbricht, N. S. Sariciftci, C. J. Arendse, E. Iwuoha and M. C. Scharber, J. Mater. Chem. C, 2017, 5, 1714.

39 S. Y. Sun, T. Salim, N. Mathews, M. Duchamp, C. Boothroyd, G. C. Xing, T. C. Sum and Y. M. Lam, Energy Environ. Sci., 2014, 7, 399.

40 A. Shinde, R. Gahlaut and S. Mahamuni, J. Phys. Chem. C, 2017, 121, 14872. 